\title{
UN CAZ DE DIVERTICUL DUODENAL LA COPIL
}

\section{Bauer Adalbert ${ }^{1}$}

${ }^{1} S C M$ Caritas Medica

Address for correspondence / Adresa de corespondență:

\section{Title: One Case of Duodenal Diverticulum at Child \\ Abstract}

A 15 years old teenager, with a relapsing abdominal ache from 6 to 8 years, and a mild digestive discomfort, was undergone at an digestive way radiological examination. With this occasion, a solitary diverticulum of duoden stand out, whose radiological appearance we breafly present. At the duodenum-gall bladder-pancreas junction, in case of churlish pain with abdominal aches, squeamishness, vomits, fullness sensation, apart from common pathology of ulcer, inflammation, parasitical infestation, enzymopaties, we must think about a complicated duodenal diverticulum.

Keywords: abdominal aches, duodenum, diverticulum, radiological examination.

\section{Rezumat}

Un adolescent de 15 ani, având o suferință abdominală recidivantă de 6-8 ani, cu un disconfort digestiv moderat, nealarmant, a fost supus unei examinări radiologice gastrointestinale. Cu această ocazie se evidențiază un diverticul solitar al ansei duodenale, ale cărui aspecte radiologice le prezentăm pe scurt. La nivelul răspântiei duodeno-veziculo-pancreatice, în cazul persistenței unei suferințe rebele cu dureri abdominale, grețuri, vărsături, senzație de plenitudine, pe lângă patologia obișnuită ulceroasă, inflamatorie, infestații parazitare, procese disenzimatice, trebuie să ne gândim și la un diverticul duodenal complicat.

Cuvinte cheie: dureri abdominale, duoden, diverticul, examen radiologic

\section{Introducere în temă}

În cadrul patologiei abdominale cronice cu localizare la nivelul răspântiei pancreatico-duodenale, trebuie să ne gândim pe lângă ulcerul duodenal, duodenită, colecistită, pancreatită cronică și la un diverticul duodenal complicat sau necomplicat.

Okinczyc afirmă: un diverticul al duodenului care se manifestă clinic este întotdeauna un diverticul complicat. Totuși în cazul descoperirii unui diverticul, nu trebuie să atribuim direct acestuia tulburările semnalate, ci numai după ce am exclus leziunile organelor vecine: veziculă biliară, stomac, colon, apendice, etc.

Nelson afirmă că la copii diverticulul duodenal congenital evoluează asimptomatic, doar în unele cazuri determinând un disconfort digestiv, asociat cu o colită spastică. 


\section{Discuții}

Zollinger [1] și Hove menționează că frecvența diverticulului duodenal variează între 0,85\% și $33 \%$ la diferitele populații. Witcoomb [2] citează un procent între 1-6 \% la cazurile depistate radiologic, iar la autopsii între $2-22 \%$.

Frik [5] subliniează că marea majoritate a diverticulilor adevărați ai adultului, în realitate sunt modificări congenitale a peretelui duodenal, de asemenea diverticulul extern al ansei duodenale este cu mare probabilitate o duplicație parțială a duodenului, cum se întâmplă în cazul diverticulilor giganți ai peretelui posterior al esofagului, sau în marea curbură a stomacului; acest tip de diverticul duodenal este foarte rar, precum diverticulii juxtabulbari.

În cadrul sindromului dureros abdominal cronic, o importanță deosebită au complicațiile diverticulului:

-de ordin mecanic, în general cele de compresiune, fie pe duoden, datorate dimensiunii exagerate diverticulului, fie pe canalele biliare sau pancreatice, datorate vecinătății lor.

-inflamatorii, de natură ulceroasă sau de natură infecțioasă (colangită, pancreatită), care pun probleme din cele mai dificile de diagnostic în patologia abdominală a copilului.

Diagnosticul radiologic al diverticulului extern îl vom expune în cazul prezentat.

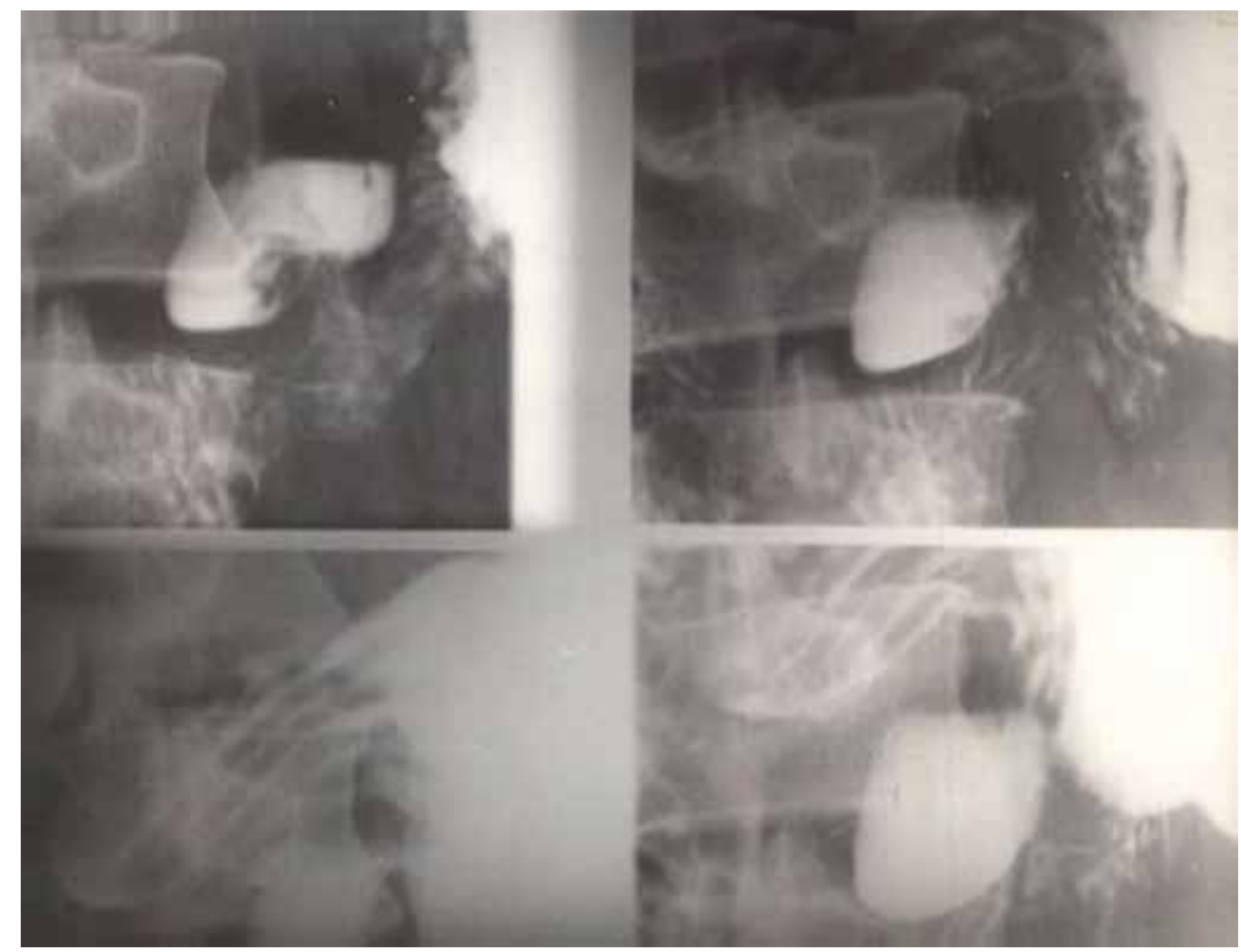

\section{Examen radiologic baritat}

În interiorul cadrului duodenal se găsește un plus de umplere de $2 \times 3 \mathrm{~cm}$, bine conturat, cu nivel orizontal la polul superior, opacifiat printr-un pedicul îngust din duoden transversal, situat în treimea medie.

Radiologic, condiția pentru vizualizarea diverticulului este permeabilitatea orificiului diverticular. În cazul unui stomac alungit, diverticulii sunt mai greu decelabili, fiind acoperiți, de aceea trebuiesc căutaţi în mai multe incidențe. 
Aspectele radiologice ale diverticulului sunt opacitate juxta-duodenală sau imagine hidro-aerică. Contururile sunt nete, bine delimitate și regulate. Pediculul diverticular poate fi vizibil. Imaginea diverticolului este influențată de palpare (semnul Booneau). Unii diverticuli duodenali se evacuează imediat, alţii persistă, golirea fiind condiționată de lărgimea și poziția gâtului diverticular.

Diverticulul intern sau intraluminal al duodenului este o malformație congenitală a cadrului duodenal cu o frecvență rară (după Heilbrun și Boyden).

Acuzele clinice sunt grețuri, vărsături, dureri în regiunea epigastrică, senzație de plenitudine; debutează la vârsta copilăriei (Kinzer, Meyer, Bargon, Curtis), cu toate acestea în perioada copilăriei s-au descris cazuri izolate (Braun). Examinarea radiologică convențională este suficientă de regulă pentru decelarea diverticulului intraluminal. Diagnosticul radiologic se completează prin duodenografie hipotonă.

Evidențierea unui diverticul duodenal atrage după sine necesitatea căutării diverticulozei intestinului subțire și a cadrului colic, mai ales dacă persistă o simptomatologie clinică imprecisă (Brauner).

Diverticulul duodenal cu toate că în majoritatea cazurilor nu se manifestă simptomatic, prin polimorfismul simptomatologiei pe care o poate cauza, reprezintă o parte integrantă și deloc neglijabilă a patologiei abdominale cronice a copilului.

\section{Concluzii}

1. Diverticulul duodenal în marea majorite a cazurilor evoluează fără simptome clinic manifeste

2. Când se manifestă clinic, este vorba de un diverticul complicat

3. La nivelul răspântiei duodeno-veziculo-pancreatice, în cazul persistenței unei suferințe rebele cu dureri în regiunea epigastrică, grețuri, vărsături, senzație de plenitudine, pe lângă patologia obișnuită ulceroasă, inflamatorie, infestații parazitare, procese disenzimatice, trebuie să ne gândim și la un diverticul duodenal complicat

4. Existența unui diverticul duodenal se poate pune în evidență printr-un simplu examen radiologic baritat gastroduodenal, dar presupune experiență din partea radiologului

5. Evidențierea unui diverticul duodenal atrage după sine necesitatea căutării diverticulozei intestinului subțire și a colonului.

\section{Bibliografie}

1. Zollinger, LM. Duodenal diverticulum, Textbook of Surgery, Ed. Saunders WB, Philadeplhia-London, 1965, 667-668

2. Witcoomb, J.C. Duodenal diverticula, Arch Surg, 1964;68:275

3. Bauer, A. Cercetări privind rolul modificărilor duodeno-veziculo-pancreatice în afecțiunile abdominale cronice a copilului. Teză de doctorat, 1977

4. Guerrier, H, A case of Intraluminal Divericulum of the duodenum, Brit J Surg, 1972;19(4):324

5. Frik, W, Les anomalies congenitales du duodenum y compris les diverticules. Acta Gastroent Belgica, 53(2):102-109

6. Croisielle, M. Intraluminal diverticulum of the duodenum, J Radiol Electrol, 1971;53,7:569 